\title{
Keran Air Plug-in Otomatis
}

\author{
M. R. Romadhan*, A. Jefiza, M. Arifin, dan I. K. L. N. Suciningtyas \\ Politeknik Negeri Batam, Batam, Indonesia
}

*Email: rizkimdh79@gmail.com

\begin{abstract}
Abstrak - Salah satu upaya dalam penghematan air adalah dengan menggunakan air sehemat mungkin. Upaya tersebut dapat di lakukan dengan memanfaatkan sistem keran air otomatis. Keran akan menutup secara otomatis saat tidak diperlukan. Tujuan penelitian ini adalah membuat keran dengan sistem otomatis yang dapat menyala/mati sesuai dengan ada/tidaknya objek. Keran otomatis ini dibuat dengan menggunakan modul sensor infared (IR) untuk mendeteksi objek berupa tangan manusia. Pemrosesan data dilakukan menggunakan mikrokontroler Atmega328P. Motor servo MG996R digunakan untuk memutar katup pada ball valve yang terdapat di dalam pipa Polyvinyl Chloride (PVC) berdiameter $1 / 2$ inci sehingga aliran air dapat dibuat on/off. Hasil percobaan menunjukkan bahwa keran otomatis ini dapat bekerja dengan baik dengan rentang penginderaan sensor $0 \mathrm{~cm}$ s.d $10 \mathrm{~cm}$. Daya yang digunakan adalah $0.73072 \mathrm{~W}$ (pada saat stand-by) dan 0.712776 W (pada saat keran berputar). Tekanan minimum yang dibutuhkan adalah 0 Pa (Air tetap dapat mengalir walaupun tanpa adanya tekanan).
\end{abstract}

Kata Kunci: ATmega328P, infrared, keran otomatis, Arduino.

\section{PENDAHULUAN}

AIR merupakan salah satu kebutuhan dasar setiap makhluk hidup, terutama manusia. Air dimanfaatkan baik pada kegiatan sehari seperti berwudhu, mencuci tangan, dan sebagainya. Dengan semakin besarnya jumlah penduduk, maka upaya penghematan air perlu terus dilakukan. Tanpa adanya penghematan, pasokan air akan terus menerus berkurang [1][3].

Salah satu hal yang dapat dilakukan dalam upaya penghematan air adalah dengan membuat sistem keran otomatis. Pengguna cukup meletkkan tangan pada jarak tertentu, lalu keran otomatis akan menyala. Keran akan otomatis menutup ketika tangan sebagai objek sudah tidak dideteksi lagi. Dengan penggunaanya yang praktis (tanpa perlu secara manual), keran otomatis ini cukup efektif dalam menghemat penggunaan air.

Keran otomatis telah banyak beredar di pasaran. Namun beberapa produk tidak bersifat plug-in. Keran tersebut memerlukan proses instalasi yang rumit. Beberapa produk lain mensyaratkan tekanan minimum untuk mengalirkan air. Hal ini tidak memungkinkan keran jenis ini dipasang pada tangki air yang memiliki tekanan air yang rendah. Produk lain di pasaran memiliki harga yang cukup tinggi, sehingga penggunaannya di tempat-tempat yang berpotensi boros air kurang maksimal. Berdasarkan beberapa latar belakang tersebut, penelitian ini bertujuan membuat keran otomatis yang bersifat plug-in dengan biaya yang lebih murah. Sifat plug-in yang dimiliki keran otomatis ini memudahkan pengguna dalam melakukan pemasangan keran.

\section{METODE}

\section{A. Desain Elektrik}

Gambar 1 menjelaskan diagram blok dari sistem elektrik pada keran otomatis ini. Pada penelitian ini, keran otomatis dibuat menggunakan mikrokontroler ATmega328P [4] (dalam modul Arduino Nano [5]). Modul ini dipilih karena ukurannya yang kecil.

Sensor yang digunakan untuk mendeteksi objek (tangan) adalah infrared (IR). Cara kerja sensor ini cukup sederhana. IR emitter memancarkan cahaya IR. Cahaya ini kemudian dipantulkan oleh objek di depannya. Pantulan cahaya ini kemudian diterima oleh IR receiver. Komparator LM363 menghasilkan nilai low (objek terdeteksi) atau high (objek tidak terdeteksi) berdasarkan tegangan yang dihasilkan oleh IR receiver tersebut. Saat menggunakan keran, pengguna cukup meletakkan objek (tangan) mendekati sensor IR, maka modul ini akan otomatis mendeteksinya. Sensitivitasnya jarak dapat diatur menggunakan potensiometer yang terdapat di dalam modul IR ini. Pada penelitian ini, sensor IR dapat mendeteksi halangan di depannya pada jarak $0 \mathrm{~s} . \mathrm{d} 10 \mathrm{~cm}$.

Motor servo MG996R [6] digunakan untuk menggantikan keran manual dalam memutar katup yang terletak di dalam pipa Polyvinyl Chloride (PVC). Selama sensor tidak mendeteksi objek (tangan) dari jarak yang telah di tentukan, maka keran tidak membuka. Motor servo dirancang dengan sistem kontrol umpan balik loop tertutup, berguna untuk menentukan posisi sudut dari poros output motor yang di inginkan. Motor servo terdiri atas motor direct current (DC), serangkaian gear, rangkaian kontrol, dan sebuah potensiometer. Manfaat dari serangkaian gear pada poros motor DC ialah memperlambat putaran poros dan meningkatkan torsi pada motor servo. Potensiometer berfungsi sebagai penentu batas posisi putaran poros motor servo dengan perubahan resistansi saat motor 
tersebut berputar. Posisi pada poros output akan dibaca oleh sensor agar dapat diketahui apakah posisi poros yang di inginkan sudah tepat. Saat posisi belum tepat, kontrol input mengirim sebuah sinyal kendali yang akan membuat posisi poros tersebut tepat pada posisi yang diinginkan.

Keran otomatis ini menggunakan baterai Lithium-ion sebagai sumber daya listriknya. Buck converter LM2596 digunakan untuk menurunkan tegangan ke $7.2 \mathrm{~V}$ dari baterai menjadi 5V untuk menyuplai daya sensor IR dan Arduino.

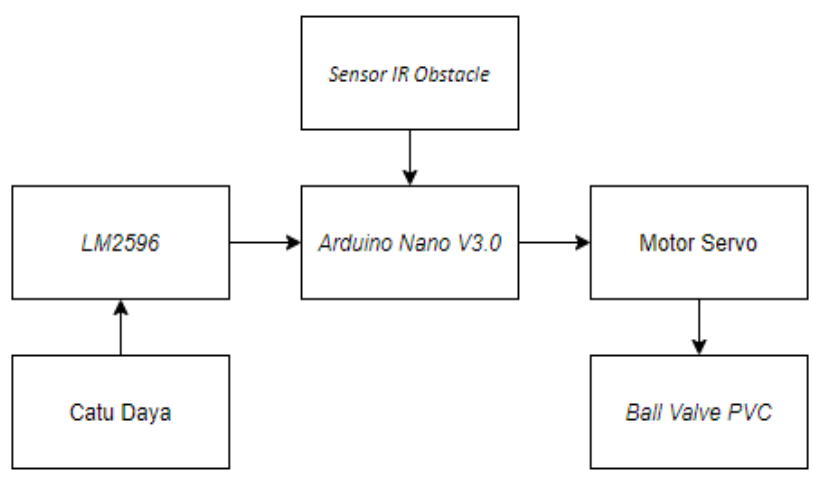

Gambar 1. Diagram sistem blok elektrik

Flowchart cara kerja keran otomatis ini dapat dilihat pada Gambar 2. Pada rentang jarak $10 \mathrm{~cm}$, modul sensor IR akan mendeteksi pergerakan atau halangan dengan memancarkan gelombang IR. Kemudian mikrokontroler akan membaca output dari modul sensor IR tersebut. Setelah itu, mikrokontroler menggerakkan motor servo untuk memutar katup keran untuk membuka aliran air. Jika sensor tidak mendeteksi adanya pergerakan di dalam rentang $10 \mathrm{~cm}$, maka katup menutup dan keran berhenti mengalirkan air.

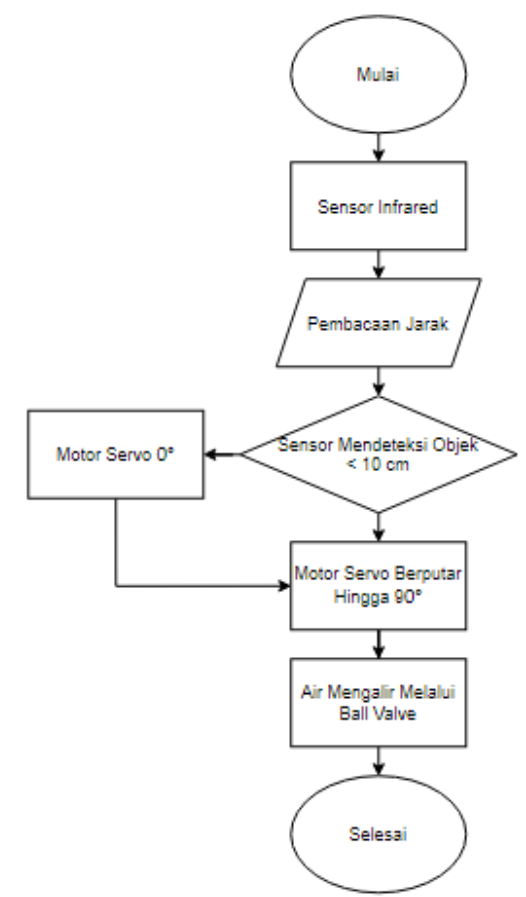

Gambar 2. Flowchart cara kerja keran otomatis

\section{B. Desain Mekanik}

Gambar desain mekanik keran ini dapat dilihat pada Gambar 3. Gambar 3(a) dan 3(b) merupakan gambar dari produk atau bagian yang akan disambungkan antara katup berupa ball valve dan motor servo. Desain mekanik ini sederhana, namun cukup kuat untuk menahan setiap putaran pada katup.Penyambungan motor dan sensor IR menggunakan part seperti di gambar 3(b). Desain ini cukup kuat untuk membuat plug bagian dalam ball valve berputar, sehingga air dapat mengalir. Gambar 3(c) merupakan casing untuk rangkaian pengendali. Bagian ini terpisah dengan keran otomatisnya sehingga dapat menghemat tempat dan tidak terlalu besar. (a)

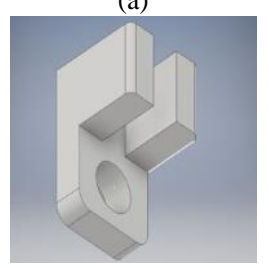

(b)

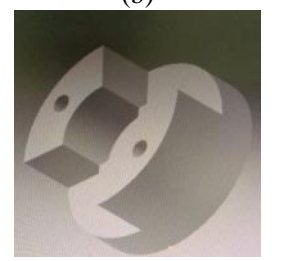

(c)

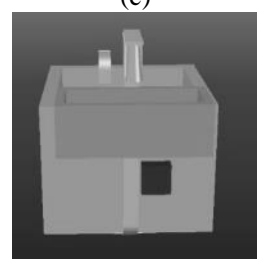

Gambar 3. Desain mekanik: (a) Holder untuk motor servo dan katup, (b) Konektor pemutar katup; (c) Casing rangkaian pengendali

\section{HASIL DAN ANALISIS}

Keran otomatis yang telah dibuat dapat dilihat pada Gambar 4 dan 5. Keran ini akan diuji berdasarkan keandalan, konsumsi daya, dan keberfungsiannya.

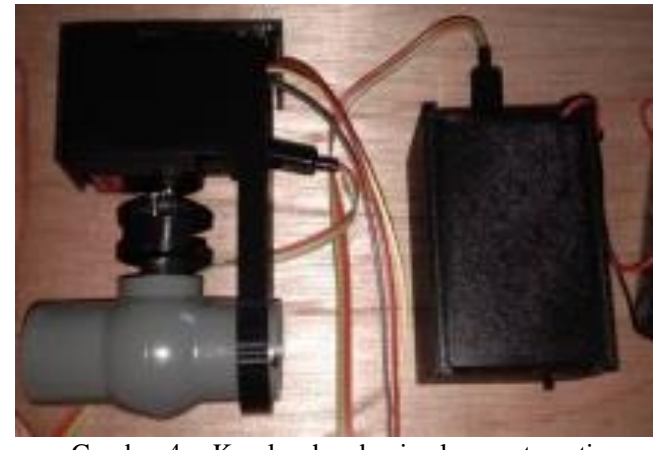

Gambar 4. Keseluruhan bagian keran otomatis

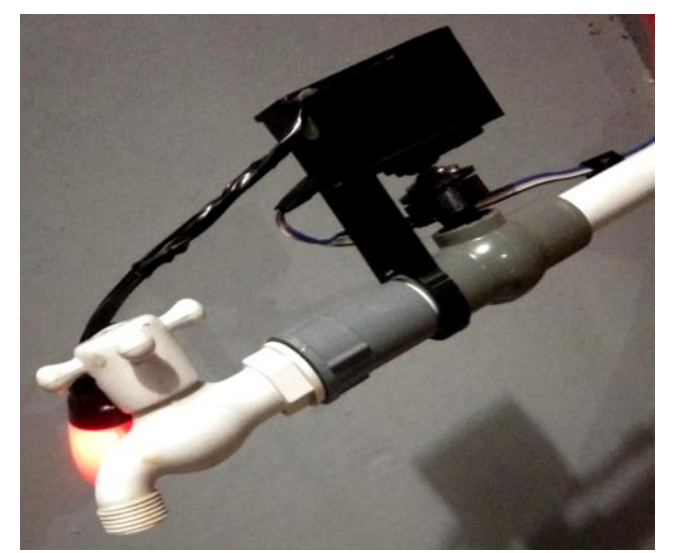

Gambar 5. Pemasangan keran otomatis yang bersifat plug-in 


\section{A. Pengujian Keandalan Alat}

Pengujian dilakukan dengan cara menggerakkan keran on dan off secara berulang-ulang sebanyak 45 kali dalam rentang waktu 45 menit. Dalam tiap menitnya, keran diset dalam posisi terbuka selama 30 detik dan tertutup selama 30 detik. Berdasarkan pengujian, alat dapat berfungsi dengan baik. Motor servo tidak mengalami masalah (seperti adanya panas atau berhenti berputar).

\section{B. Pengukuran Konsumsi Daya}

Pengujian dilakukan dalam dua kondisi: 1) Katup keran dalam keadaan diam (kondisi stand-by) dan 2) Katup keran dalam keadaan bergerak. Pengambilan data masing-masing dilakukan sebanyak lima kali dalam kondisi tanpa air. Gambar 6 memperlihatkan setup pengujian.

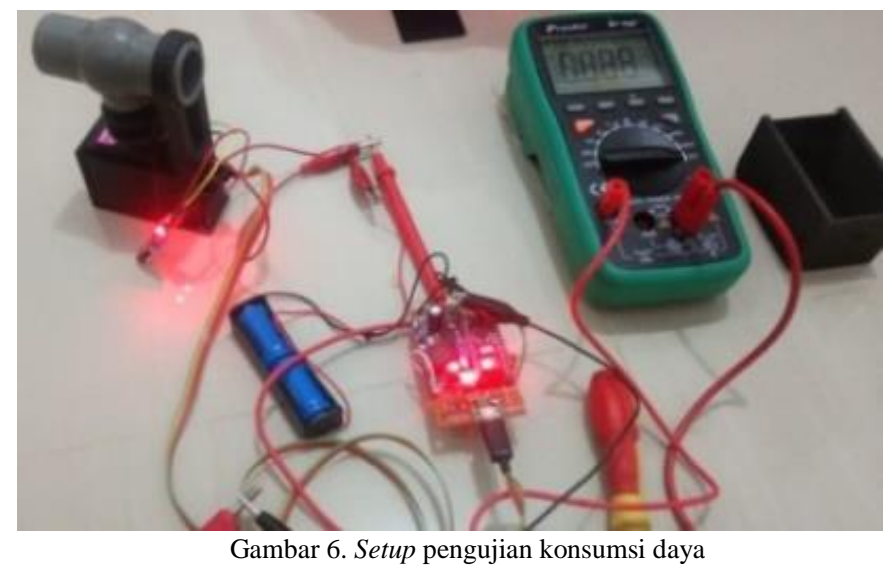

Hasil pengukuran konsumsi daya pada saat katup keran diam $\left(P_{O F F}\right)$ dapat dilihat pada Tabel I. Sedangkan hasil pengujian pada saat katup keran bergerak $\left(P_{O N}\right)$ dapat dilihat pada Tabel II. $P_{O F F}$ rata-rata yang dihasilkan adalah 0.67307 Watt, sedangkan $P_{O N}$ rata-rata yang dihasilkan adalah 0.71278 Watt. Selama proses pengukuran, motor servo tidak mengalami masalah.

\section{Pengujian Fungsi Alat}

Pengujian fungsi alat dilakukan dengan cara mengoperasikan alat dalam rentang jarak tertentu. Pengujian dilakukan sebanyak 13 kali. Daya berasal dari baterai. Hasil pengujian dapat dilihat pada Tabel III. Hasil pengujian menunjukkan bahwa motor akan berputar untuk membuka katup keran untuk mengalirkan air saat jarak dari tangan ke sensor hingga $10 \mathrm{~cm}$. Saat jarak tersebut melebihi $10 \mathrm{~cm}$ motor tidak berputar sehingga katup tidak mengalirkan air.

Pengujian keran juga dilakukan secara horizontal untuk memastikan bahwa air tetap dapat mengalir tanpa tekanan minimum. Hasil pengujian ini membuktikan bahwa dengan penggunaan katup berupa ball valve, air tetap dapat mengalir tanpa tekanan minimum. Ini salah satu kelebihan yang dimiliki keran ini dibandingkan produk sejenis di pasaran.
TABEL I

HASIL PENGUJIAN SAAT KATUP KERAN DIAM

\begin{tabular}{|c|c|c|c|}
\hline Pengujian ke- & Tegangan $(\mathrm{V})$ & Arus (A) & $P_{\text {OFF }}(\mathrm{W})$ \\
\hline 1 & 7.83 & 0.089 & 0.69687 \\
\hline 2 & 7.79 & 0.084 & 0.65436 \\
\hline 3 & 7.79 & 0.085 & 0.66215 \\
\hline 4 & 7.77 & 0.091 & 0.70707 \\
\hline 5 & 7.77 & 0.083 & 0.64491 \\
\hline \multicolumn{3}{|c|}{ Rata-rata } & 0.67307 \\
\hline
\end{tabular}

TABEL II

HASIL PENGUJIAN SAAT KATUP KERAN BERGERAK

\begin{tabular}{|c|c|c|c|}
\hline Pengujian ke- & Tegangan (V) & Arus (A) & $P_{O N}(\mathrm{~W})$ \\
\hline 1 & 7.81 & 0.098 & 0.76538 \\
\hline 2 & 7.77 & 0.086 & 0.66822 \\
\hline 3 & 7.76 & 0.089 & 0.69064 \\
\hline 4 & 7.74 & 0.093 & 0.71982 \\
\hline 5 & 7.74 & 0.093 & 0.71982 \\
\hline \multicolumn{3}{|c|}{ Rata-rata } & 0.71278 \\
\hline
\end{tabular}

TABEL III

HASIL PENGUJIAN FUNGSI ALAT

\begin{tabular}{|c|c|c|c|}
\hline \multirow{2}{*}{ Percobaan ke-- } & \multicolumn{2}{|c|}{ Pengujian Sensor IR } & \multirow{2}{*}{ Status Motor } \\
\cline { 2 - 3 } & Jarak tangan-sensor $(\mathrm{cm})$ & Status Sensor & \\
\hline 1 & 1 & ON & Berputar $90^{\circ}$ \\
\hline 2 & 2 & ON & Berputar $90^{\circ}$ \\
\hline 3 & 3 & ON & Berputar $90^{\circ}$ \\
\hline 4 & 4 & ON & Berputar $90^{\circ}$ \\
\hline 5 & 5 & ON & Berputar $90^{\circ}$ \\
\hline 6 & 6 & ON & Berputar $90^{\circ}$ \\
\hline 7 & 7 & ON & Berputar $90^{\circ}$ \\
\hline 8 & 8 & ON & Berputar $90^{\circ}$ \\
\hline 9 & 9 & ON & Berputar $90^{\circ}$ \\
\hline 10 & 10 & ON & Berputar $90^{\circ}$ \\
\hline 11 & 11 & OFF & Tidak berputar \\
\hline 12 & 12 & OFF & Tidak berputar \\
\hline 13 & 13 & OFF & Tidak berputar \\
\hline
\end{tabular}

\section{KESIMPULAN}

Keran otomatis yang bersifat plug-in telah berhasil dibuat dan dipasang pada pipa PVC dengan ukuran $1 / 2$ inci. Konsumsi daya yang dibutuhkan adalah 0.67307 Watt pada saat katup keran diam (stand-by) dan 0.71278 Watt pada saat katup keran bergerak. Keran otomatis ini bekerja dalam rentang deteksi objek 0 s.d. $10 \mathrm{~cm}$. Tidak seperti keran otomatis lainnya, dengan menggunakan keran ini air tetap dapat mengalir tanpa tekanan minimum.

\section{UCAPAN TERIMA KASIH}

Penulis mengucapkan terima kasih kepada Pusat P2M Politeknik Negeri Batam dan Pengelola Pasar Mitra Jaya, Batam yang telah memberikan bantuan untuk pembuatan dan pengujian keran otomatis ini. 


\section{REFERENSI}

[1] S. Suhardi, "Keran Air Otomatis Pada Bak Mandi Berbasis Arduino Uno Menggunakan Sensor Ultrasonic," Algoritm. J. ILMU Komput. DAN Inform., vol. 3, no. 1, p. 48, Apr. 2019.

[2] L. R. La Raufun and S. Ardiansyah, "PROTOTYPE PENGONTROL PENGISIAN TANDON AIR SECARA PARALEL

MENGGUNAKAN SOLENOID VALVE BERBASIS ATMEGA 2560," J. Inform., vol. 7, no. 2, Dec. 2018.

[3] M. Amin, "InfoTekJar:Jurnal Nasional Informatika dan Teknologi Jaringan Sistem Cerdas Kontrol Kran Air Menggunakan Mikrokontroler Arduino dan Sensor Ultrasonic," InfoTekJar J. Nas. Inform. dan Teknol. Jar., vol. 4, no. 2, pp. 55-59, Apr. 2020.

[4] Atmel, "ATmega328/P [Datasheet]," AVR Microcontrollers, 2016.

[5] Arduino, "Arduino - ArduinoBoardNano," Arduino. 2009.

[6] Towe Pro, "Data Sheet MG996R High Torque Metal Gear Dual Ball Bearing Servo," Electonic Caldas, 2015. 